Article

\title{
Competitiveness and Its Impact on Sustainability, Business Environment, and Human Development of EU (28) Countries in terms of Global Multi-Criteria Indices
}

\author{
Dana Kisel'áková ${ }^{1}$, Beáta Šofranková ${ }^{1, *} \mathbb{C}$, Miroslav Gombár ${ }^{2}$, Veronika Čabinová ${ }^{1}$ and \\ Erika Onuferová ${ }^{1}$
}

1 Department of Finance, Faculty of Management, University of Prešov in Prešov, Konštantínova 16, 08001 Prešov, Slovakia; dana.kiselakova@unipo.sk (D.K.); veronika.cabinova@smail.unipo.sk (V.Č.); erika.onuferova@smail.unipo.sk (E.O.)

2 Department of Management, Faculty of Management, University of Prešov in Prešov, Konštantínova 16, 08001 Prešov, Slovakia; miroslav.gombar@unipo.sk

* Correspondence: beata.sofrankova@unipo.sk

Received: 25 April 2019; Accepted: 13 June 2019; Published: 18 June 2019

check for updates

\begin{abstract}
In this paper, the following research problem was addressed: Is there a significant economic impact of multidimensional specified competitiveness within the EU (28) countries on the competitive business environment, human development, and sustainable growth? Based on the mentioned research problem, we formulated the aim of paper: To detect the significant interrelations among the assessment of global competitiveness, business environment as well as human development in the EU (28) countries for the period of 2006-2017. To address these problems, the methodology of global multi-criteria indices, namely the global competitiveness index (GCI), doing business index (DBI), and human development index (HDI), as well as panel analysis and non-linear regression analyses with ANOVA, were applied. The panel analysis results suggest that there is a direct linear relationship between the GCI and HDI. Moreover, the impact of the DBI on the change in the GCI score was not confirmed. We identified the main areas of countries' interest, and important economic and statistical significant relations of competitiveness by creating three models: The GD model (constructed by GCI and DBI scores), GH model (GCI and HDI scores), and GDH model (GCI, DBI and HDI scores). Based on the results, all interrelations were confirmed. However, the highest extent of variability for the explanation of the selected data was recorded in the case of the GDH model $(87.12 \%)$. We detected the impact of the business environment and human resources as competitive advantages on global macroeconomic competitiveness. As the business sector in EU (28) countries is represented mainly by small and medium-sized enterprises (SMEs), enterprise activities play a key role in the process of sustainable competitive economic development. Moreover, human resources are considered to be another important driver of the internationalization of European SMEs.
\end{abstract}

Keywords: multi-criteria indices; global competitiveness; business environment; human development; regression modelling; small and medium enterprises

\section{Introduction}

The growing openness and integration of the world has led to an increase in the importance of comparing individuals, organizations, countries, and regions. In the context of ensuring the sustainable economic development of countries, an objective assessment of the current situation, possibilities, and capabilities when compared with competitors is important. Competitiveness analysis is focused 
on identifying and characterizing decisive factors, and nowadays, considerable attention is paid to the countries' competitiveness assessment. Porter [1] belongs to the group of initiators of this research science, as he investigated business competitiveness and understood the close link between micro and macro levels. The business environment creates conditions for the competitiveness of enterprises, which is then reflected in the country's competitiveness. The basis of this system are the skills, decisions, and real performance of businesses. However, more sophisticated strategies and more productive activities require more educated people, better information, more effective government decisions, better infrastructure, developed research institutions, and so on. Therefore, a higher quality, productivity, and market success of business production is reflected in the country's export performance, in its economic growth, and, ultimately, in the higher standard of living of its inhabitants.

The many years of crises that lie behind us-the financial crisis, the euro area sovereign debt crisis, and now the migration crisis-have put Europe to the test. National interests of member states have regained prominence and policy debates are often dominated by questions of competitiveness. Moreover, integrated markets and human resources are the backbone of Europe's prosperity.

The European economy is currently facing a long-awaited dynamic recovery. Consumer and business confidence are rising, and industrial production growth is accelerating. Even more encouragingly, the upturn is broad-based, driven not only by domestic consumption but increasingly by investment and export stimulus from a growing global economy. However, these short-term successes should not disguise the long-term challenges facing the European economy. Therefore, the recent economic recovery gives no grounds for complacency. Instead, the opportunity must be taken to improve the potential for sustainable long-term growth in Europe [2].

Decisive measures are needed to raise Europe's competitiveness in order to support higher levels of productivity, employment, and prosperity. The effects of the crisis have exacerbated structural weaknesses and contributed to a legacy of economic and policy challenges that need to be tackled. These challenges have been made more pressing by the unprecedented rise in migration witnessed over the past year, and which-in all likelihood-will continue in the near future. The way to tackle these challenges is through deeper European market integration, further cohesion and convergence, strengthening and development of markets, and an increase of efforts to make Europe stronger and more competitive. Openness, innovation, skills development, and the free movement of goods and services, labor, and capital are the drivers of Europe's competitiveness, growth, and prosperity. Furthermore, according to the European Investment Bank, gaps exist in European investment in business innovation and investment in human capital is also needed to sustain European competitiveness over the long-term [3].

As reported by [4], international competitiveness has long been a major preoccupation of economic thought and has been receiving increasing attention from scientists, policy makers, businesses and the general population alike. According to [5], the analysis of competitiveness allows an appreciation of the extent to which the various economies of the world's countries have managed to face economic challenges. The competitiveness has been and remains a priority in the plan of the scientific debate, but also a major concern for all world economies. Economic policies and institutional reforms were accepted as basic tools for an increase in intensity of the competitiveness and sustainable performance. A country's competitiveness is variously measured and the level of competitiveness comprises many variables of economic prosperity. The various determinant factors of competitiveness and country specific macroeconomic indicators allow classification of the world economies in different stages of development.

The main aim of this paper was to detect the significant interrelations among the assessment of global competitiveness, business environment as well as human development in the EU (28) countries for the period of 2006-2017. In addition, we also analyzed other economic relations and implications on the global scale. What is the level of Europe's potential in the context of long-term global competitiveness? Is Europe an equally attractive investment place for entrepreneurship and small and medium-sized enterprises (SMEs)? What about the effect of human resources' quality and 
demographic trends in Europe? Is there a significant economic impact of the business environment and human capital on an increasing multidimensional perceived competitiveness within the EU (28) countries? In this research paper, we focused on finding answers to the above questions and SMEs related issues. The paper is a more detailed and in-depth continuation of our previous research studies concerning the global competitiveness and economic growth of European countries [6].

Our findings in this study indicate the important impact of the quality of a business environment measured by the DBI and an effective human resources movement measured by the HDI as competitive advantages on global competitiveness.

The paper is organized as follows. Firstly, we review the empirical literature related to the issue concerning competitiveness, the business environment, and human development on the global scale. These closely interconnected economic categories are analyzed in the form of internationally known multi-criteria indices. In the next chapter, we briefly introduce the methodology and analyzed data. The initial empirical part of the study focused on the development analysis of the above mentioned indices within the EU (28) member states over the years 2006 to 2017. The following partial analyses evaluate the results of individual regression models designed in order to detect the significant interrelations among the assessment of global competitiveness, the business environment as well as human development in the EU (28) countries during the monitored period. In line with the performed analyses, the last partial analysis was focused on the verification of the designed models and prediction of the GCI score for 2018 on the basis of the DBI. The last two chapters discuss the main results in the broadest context possible and also highlight the limitations and future research directions.

\section{Literature Review}

Nowadays, many international organizations and institutions publish well recognized annual reports focusing on evaluating a country's competitiveness, growth, sustainability, etc. from different perspectives to create rankings of countries based on the effect of a range of various economic and noneconomic factors. However, as reported by [7], the economic indicators and other indices measuring overall development describe local development trajectories differently and according to [8], there is a high risk that the increase in competitiveness is short-lived/merely temporary, without provision for the desired long-term structural change.

\subsection{Global Competitiveness Index (GCI)}

The concept of a country's competitiveness still does not have a clear and straightforward meaning and remains ambiguous. Different economists stress various aspects of the concept and use a number of different methods to evaluate how competitive a country is [9]. Annually, the World Economic Forum [10] introduces the global competitiveness rankings through the global competitiveness index (GCI) as the most extended tool for a country's competitiveness assessment. Many empirical researches are devoted to the analysis of an overall score of the GCI, to the evaluation of individual factors and indicators of economic growth, in order to detect the most influential variables and to provide specific recommendations to improve the actual level of a country's competitive position. The issue of national competitiveness is still in the center of different subjects' attention, so the methodology of the indexes trying to capture its essence is constantly changing. For this reason, [11] focused on describing the most important changes that have been made within the index methodology in the last report of 2018 , and assessed whether the new methodology is able to better capture the real competitiveness of economies in global market conditions. In the study, [12] investigated the impact of three sub-indexes of the above-mentioned index (called basic requirements, efficiency enhancers, and innovation and sophistication factors) on the overall GCI score for the purpose of extending the added value in the research of global competitiveness.

In the study, [13] focused on the definition of main factors of socioeconomic development by determining the competitiveness level of EU countries and the classification of EU member states to homogenous groups based on their competitive factor endowment. The contribution of each 
factor (indicator) to the value of the GCI score using various statistical methods was evaluated by [14]. An analysis was conducted on a research sample of 41 European countries and the analysis of the competitiveness in line with the GCI helped detect the specifics of the existing regional socioeconomic differentiation compared to the average development in Europe. Based on these results, the author emphasizes that the detected characteristics should be considered in the process of building a national competitive strategy. The authors [1] studied the influence of various indicators related to the knowledge of an economy on country competitiveness in the European Union (EU). Based on the Pearson coefficient and panel-data regression models, the authors analyzed the GCI in relation to research and development (R\&D) expenditure (as a \% of gross domestic product (GDP)), percentage of population with tertiary education, lifelong learning, GDP per capita, and debt to equity. The findings highlighted the crucial role of both innovation and education as determinants of EU competitiveness and economic convergence. As reported by [15], competitiveness is today's most popular slogan and is the aspiration of nations, regions, cities, organizations, and even people. We all compete in the global market and look for our place in this vast world. However, the true meaning behind the concept of competitiveness is still not fully understood. The authors of [16] examined how worldwide governance, global competiveness, and other institutional determinants have influenced the number of accounting fraud cases in several countries. The number of fraud cases is positively influenced by a combination of institutions and policies according to the GCI results of economics. The authors believe that a better understanding of fraud detection is a potentially important element in forensic accounting analytics in the success of governance policies to enhance the development of countries.

\subsection{Doing Business Index (DBI)}

A country cannot achieve and sustain rapid economic progress without a developed economic environment [17]. The competitiveness of an economy is an integrated set of factors acting not only at the macroeconomic but also the microeconomic level. One such factor is the performance of the economy, in particular, created by an enterprise sector. Therefore, sustainable economic development is closely related to business performance and management. As reported by [18], the basic strategic objectives of each organization include long-term growth and sustainability. In a growing competitive environment, it is essential to manage the company effectively. In this regard, [19] adds that SMEs should be supported in the initial period when they have not exceeded the minimum efficient scale. As reported by [20], any company wishing to achieve prosperity and its goals not only for both its owners as well as its employees, but also for the company itself, must be informed about the recent trends and changes influencing its activity. This can be achieved provided that the company's organizational structure and operations are properly set from the point of view of the ERP (enterprise resource planning) system. In this regard, the World Bank Group [21] suggests the doing business index (DBI), which provides an objective measuring tool of business regulations for local enterprises and evaluates various aspects of business conditions. According to the study [22], in a contemporary competitive business environment, the choice of an appropriate strategy is important in an effort to further the development of companies. Business environments differ in every country and there is a constant debate about how a business environment should be assessed. The authors of [23] add that the business environment in transition countries is often extraordinarily challenging for companies due to constant changes in the institutional environment. As reported by [24-26], the sector of small and medium-sized enterprises (SMEs) plays a key role in all economies in a major part of the world as they contribute to the development of competitiveness and the economic growth level markedly. In today's complex and highly competitive business environment, the adoption of appropriate strategies is particularly important for SMEs $[27,28]$. In this context, the application of the concept of supply chain management (SCM) in the competitive strategies of SMEs seems to be very important. Therefore, it is essential to study the problems of SCM implementation in SMEs, as reported by [29]. In the context of enterprise competitiveness, the authors of [30] recommends the application of selected methods and models of strategic business performance management. The key tool in increasing the 
overall performance of the enterprise in the selected Slovak industries seems to be the employment of a system of strategic performance management, supported by a knowledge-based business intelligence information system.

The authors of [31] searched for a balance between the three pillars of sustainable development and competitiveness, taking into account economic, social, and environmental criteria in order to attract investments into the business environment. The authors [32] focused on the service quality issue. The purpose of the paper was to explore the relationship between the service quality and the firms' global competitiveness in the service industry. Two types of robust regressions for panel data were employed in the empirical model estimation. The findings detected that service quality significantly drives global competitiveness. The issue of business performance expressed by the ease of doing business in relation to the competitiveness of countries was addressed by [33]. In today's business environment, foreign direct investments (FDIs) are an important factor of competitiveness across the globe. The authors applied the above mentioned indicators and the findings confirmed that the ease of doing business enables inward FDI through better contract enforcements, obtained credit, and the registration of property. The authors [34] investigated the impact of some macroeconomic, individual, and business environment-related factors on the dynamics of entrepreneurial activity in 18 European Union countries for a period of 14 years (2002-2015). The authors used three regression models and applied a panel data fixed effect model approach. The results of the study highlighted that the inflation rate, foreign direct investments, access to finance, and total tax rate are the main macroeconomic determinants of entrepreneurship. The authors [35] focused on the development of an integrated data envelopment analysis (DEA) model to explore the most productive manner through which Vietnam exports goods to other countries. Exploring the most productive export business will help us achieve another goal of this study, which is the selection of international market efficiencies. The variables used for this analysis included the exports, total exports, import tariff, dollar exchange, and the ease of doing business. The findings show that for the selection of the export market, the three countries that were the most consistently efficient during 2014 to 2017 were Malaysia, Singapore, and the United States. As reported by [36], the integration of knowledge and enhancement of performance are related to competitiveness, not only at the business level. The authors highlighted four dynamic aspects that enhance a firm's performance, as well as firms' and countries' competitiveness: Organizational learning, knowledge integration, technological capability, and technology relatedness. A high-quality business environment that creates the conditions for long-term economic growth is a basic precondition for business development and increasing the competitiveness of a country. Moreover, the quality of the business environment is decisive for the inflow of investments into the country. For this reason, the author [37] assessed the Slovak business environment over the 2012 to 2018 period, based on individual components of the business environment. Elements of the business environment in the country involve a legislative framework for business and law enforcement, administrative and financial (tax and fee) burdens, interference with business freedom, and business infrastructure (conditions, quality and availability of key factors of production, and business services). It is clear from this that the business environment is a complex variable, including many areas. According to the paper's findings, the author stated that the decisive areas determining the business objectives and decisions in Slovakia include the area of the financing of companies and capital; employment, unemployment, and the quality of human resources; social policy in the context of the functioning of the labor market and its legislation; business and tax policy in the context of public finance policy; market regulation; market entry and exit conditions; antitrust policy; subsidy and subsidy policy; licensing policy; and certification and property registration system. However, there are also obstacles that investors can perceive very sensitively in the future and may be a competitive disadvantage for Slovakia as an investor target, such as: Judiciary, high rates of taxation, the outflow of educated labor force abroad, and the ethics of domestic companies. Furthermore, the author concluded that a sustainable business environment constantly innovates and simplifies individual indicators affecting businesses on the market. 


\subsection{Human Development Index (HDI)}

Nowadays, human resources have become the most important part of the competitive advantage of enterprises and countries, which leads to economic growth. The process of human development should at least create an environment for people, individually and collectively, to develop to their full potential and to have a reasonable chance of leading productive and creative lives. Stress promoting the effect of human capital on economic growth has also gained theoretical and empirical support. [38] As reported by [39], if human capital means professional expertise, skills, and health that enhance individual creative capacities, and the ability to produce economic-social goods to allow future income generation, investment in human capital translates into higher productivity for the individual who owns such capital. Then, people, nations, and economies are more connected than ever. In this regard, the human development index (HDI) was composed. Human development indices and indicators are the product of the Human Development Report Office (HDRO) [40] at the United Nations Development Program (UNDP). The HDI is a comprehensive indicator used for measuring the social development of different countries or regions, reflecting three major dimensions of human development: Income, health, and education [41]. The authors [42] state that the competitiveness of countries is influenced by the human development level and requires government actions to improve the quality of life of its citizens. The problem of dimensioning this development in relation to government actions determines the objective of analyzing the existence of a correlation between the indicators of governance of the countries calculated by the World Bank (WGI) and the HDI calculated by the United Nations. To investigate this hypothesis, correlation analyses were performed between the HDI and the six governance dimensions of the WGI. The results of the research confirmed the existence of a significant positive correlation between the HDI and the WGI, thus establishing an understanding of the complementarity of these indicators and the possibility of their use in the establishment of governmental actions.

The issue of human development was addressed by [43]. The purpose of the study was to explore the relationship between economic growth, terrorism, and the human development index for the period of 1990 to 2016. An empirical result from the autoregressive distributive lag model (ARDL) showed that economic growth contributes to human development. Furthermore, the findings indicated that terrorism worsens the human development index. The novel findings of the study can help government officials and policymakers towards the productive use of funds. The HDI is one of the most widely used composite indicators of socio-economic development. However, many scholars suggest the addition of a sustainability dimension. For this reason, the authors [44] introduced the sustainable HDI (SHDI), based on a multidimensional synthesis of indicators (MSI), a new class of indexes that can be used for monitoring sustainable human development (SHD). The economic and competitive level of countries is mostly measured with macroeconomic aggregates, such as the gross national product or gross national income per capita. The authors [45] investigated the determinants of economic growth and the living standard levels across 15 Asian countries from 2006 to 2016. The HDI was selected as a personal welfare development index and used as a subordinate variable of the panel. The findings showed that specific programs of public service, medical care, and welfare are more likely to directly affect the HDI. While the total amount of official development assistance still has a positive impact on the HDI, education, health, and the public service field, aids also have significant effects on the HDI. The need to reflect disaster risk in development indicators was investigated by [46]. Using the HDI as an example, the authors demonstrated how such an indicator as the RHDI (risk-adjusted human development index) may be constructed with another readily available global dataset, allowing one to jointly measure the evolution of disaster risk and development. In this commentary, they asked how the incorporation of disaster risk measured relative to a country's capacity to cope affects its human development measured across the three dimensions of health, education, and standard of living.

The authors [47] pointed to the fact that different sustainability indicators tend to reflect different or even converse outcomes in terms of countries. A careful comparative study is needed to clarify whether these indicators are actually coherent with each other. Thus, the authors analyzed and compared five sustainable development indicators and a Pearson correlation was used to make a comparative study 
among them. It was found that the human development index (HDI), environmental performance index (EPI), and environmental sustainability index (ESI) provide a short-term local perspective on "sustainability", while the emergy-based sustainability index (EmSI) and surplus biocapacity are more long-term and global in their perspective. The HDI, EPI, and ESI have a more social and economic focus, including indicators whose dynamics are disjoined from the natural one. The authors [48] designed a new approach for evaluating and ranking European countries by using the interrelation between two groups of criteria, associated with the HDI and the world internal security and police index (WISPI). The proposed methodology could be applied to develop the management policy of countries, as well as their evaluation and ranking by using various indices, criteria, and procedures. In this context, the authors [49] studied the creative capacity of 28 European countries in the period 2005-2014. The authors constructed a creativity index based on the 3Ts concept of talent, technology, and tolerance as the key components of creativity. The creativity index was compared to the world happiness index (WHI), GDP per capita, and human development index (HDI). Using cross-sectional analyses, it showed the relatively strong correlation among the indexes and as well as evidence that the creative capacity is clustered geographically.

\section{Materials and Methods}

The main aim of this paper was to detect the significant interrelations among the assessments of global competitiveness, the business environment as well as human development in the EU (28) countries for the period 2006-2017.

The input variables of the created models consisted of the following indices: The global competitiveness index (GCI), doing business index (DBI), and human development index (HDI). In this regard, the DBI analyzes a country's business environment in terms of its attractiveness to investors; the HDI is focused on the level of human development and potential as an important factor for the development and sustainability of a country. Within the realized regression analysis, the DBI and HDI represent independent model variables, while the GCI represents the dependent variable.

The data relating to individual indices were collected based on annually published online reports over the period of 2006 to 2017 and processed by STATISTICA software (version 13).

To perform the analysis, for the aggregation of EU (28) countries, we included the following states: Austria (AT), Belgium (BE), Bulgaria (BG), Croatia (HR), Cyprus (CY), Czech Republic (CZ), Denmark (DK), Estonia (EE), Finland (FI), France (FR), Germany (DE), Greece (EL), Hungary (HU), Ireland (IE), Italy (IT), Latvia (LV), Lithuania (LT), Luxembourg (LU), Malta (MT), the Netherlands (NL), Poland (PL), Portugal (PT), Romania (RO), Slovakia (SK), Slovenia (SI), Spain (ES), Sweden (SE), and the United Kingdom (UK).

The descriptive statistics of input variables are presented in Table 1. Attention should be given to the mean, median, and standard deviation, as well as the minimum and maximum values of individual indices within the period 2006-2017. In addition, the brackets contain particular values, state abbreviations, and the year in which the minimum and maximum values were recorded.

Table 1. Descriptive statistics of the selected indices-Global Competitiveness Index (GCI), Doing Business Index (DBI), and Human Development Index (HDI). Source: own processing.

\begin{tabular}{cccccccc}
\hline & \multicolumn{7}{c}{ Descriptive Statistics (GCI DBI HDI 2006-2017 in Workbook) $\mathbf{n}=\mathbf{3 2 9}$} \\
\cline { 2 - 8 } & Mean & Median & Std. dev. & Minimum (Country) & Maximum (Country) & Lower & Upper \\
\hline GCI & 67.705 & 65.281 & 7.196 & $55.14\left(\mathrm{EL}_{2012}\right)$ & $82.29\left(\mathrm{FI}_{2006}\right)$ & 61.784 & 74.286 \\
DBI & 72.426 & 72.989 & 7.107 & $50.07\left(\mathrm{HR}_{2006}\right)$ & $85.66\left(\mathrm{DK}_{2012}\right)$ & 66.916 & 78.060 \\
HDI & 86.685 & 86.900 & 4.059 & $75.60\left(\mathrm{BG}_{2006}\right)$ & $93.80\left(\mathrm{IE}_{2017}\right)$ & 83.550 & 90.150 \\
\hline
\end{tabular}

The panel analysis determined the relationship between the dependent variable (GCI) and independent model variables represented by the DBI and HDI. Within the panel data analysis, 
we focused on time series analysis (2006-2017) on a sample of 28 European countries, which represented a set of 329 observations.

The panel data were a combination of cross-sectional and time data. For the panel data, a time series for each entity was used within the cross-section selection. Most often, panel data is used to examine the evolution of different units from the same sector, market, or geographical unit, with a broad cross-sectional structure and only a few time periods [50-52].

The basic regression model of panel data is:

$$
y_{i t}=\beta_{1} x_{i t 1}+\beta_{2} x_{i t 2}+\ldots+\beta_{\mathrm{k}} x_{i t k}+\alpha_{1} z_{i 1}+\alpha_{2} z_{i 2}+\ldots+\alpha_{q} z_{i q}+u_{i t}
$$

where the index, $i$, denotes the cross-sectional dimension, $i=1, \ldots, n$; the index, $t$, is the time dimension, $t=1, \ldots, T$; the variables, $x_{1}$ to $x_{k}$, are explanatory variables not including the unit vector; and the variables, $z_{1}$ to $z_{q}$, represent individual effects- the diversity that can distinguish an individual or a whole group from other entities-and a possible unit vector was included here. Individual effects do not change with time. Under the above framework [53,54], three basic cases were distinguished:

1. Pooled Regression-if the individual effect is only a unit vector, which means that the single $\alpha$ parameter is a common constant, then the resulting model is:

$$
y_{i t}=\alpha+\beta_{1} x_{i t 1}+\beta_{2} x_{i t 2}+\ldots+\beta_{\mathrm{k}} x_{i t k}+u_{i t}
$$

2. Fixed Effects Model (FEM)—if the individual effects of $z_{1}$ to $z_{q}$ are unobservable but correlated with the explanatory variables, the solution is to include all effects in the estimable conditional average using the relation, $\alpha_{\mathrm{i}}=\alpha_{1} z_{i 1}+\alpha_{2} z_{i 2}+\ldots+\alpha_{q} z_{i q}$, and the resulting FEM model is:

$$
y_{i t}=\alpha_{i}+\beta_{1} x_{i t 1}+\beta_{2} x_{i t 2}+\ldots+\beta_{\mathrm{k}} x_{i t k}+u_{i t}
$$

where the fixed effect, $\alpha_{i}$, means a specific constant for each cross-sectional unit.

3. Random Effect Model (REM) - if the individual effects of $z_{1}$ to $z_{q}$ are unobservable but not correlated with the explanatory variables, the solution is a compound random component, $\varepsilon_{i}+u_{i t}$, which, in addition to the original one, also assumes a specific random component for each cross-sectional unit and REM model, which is:

$$
y_{i t}=\alpha_{i}+\beta_{1} x_{i t 1}+\beta_{2} x_{i t 2}+\ldots+\beta_{\mathrm{k}} x_{i t k}+\left(\alpha+\varepsilon_{i}\right)+u_{i t} .
$$

The Hausman specification test was used to choose between the FEM and REM models. The null hypothesis assumes that the parameter estimates of the generalized least squares method in the REM model and the least squares method in the FEM model are consistent, thus the least squares estimate is not efficient. In an alternative hypothesis, only the least squares method is consistent. If the value of the statistics is $H>\chi^{2}{ }_{c}$, then we reject the null hypothesis about the consistency of both estimators and the FEM model is more suitable. If the value of the statistics is $H<\chi^{2}{ }_{c}$, then we cannot reject the null hypothesis and the REM model will be recommended [54].

In accordance to the above mentioned theoretical approaches and the main aim of this research paper, the following hypotheses were set:

Hypotheses 1 (H1). There is a statistically significant relation between the assessment of global competitiveness (GCI) and the business environment (DBI) within the EU (28) countries.

Hypotheses 2 (H2). There is a statistically significant relation between the assessment of global competitiveness (GCI) and human development (HDI) within the EU (28) countries. 
To detect the existence of a correlation between the independent variable (GCI) and the two dependent variables (DBI and HDI), the regression analysis methodology was applied to estimate the regression model coefficients.

In the context of global competitiveness assessment, regression models have been applied in many research studies. The authors [1] studied the influence of various indicators related to the knowledge of economy on country competitiveness in the European Union (EU). Based on the Pearson coefficient and panel-data regression models, the authors analyzed the GCI in relation to research and development (R\&D) expenditure (as a \% of GDP), the percentage of the population with tertiary education, lifelong learning, GDP per capita, and debt to equity. The findings highlighted the crucial role of both innovation and education as determinants of EU competitiveness and economic convergence.

The authors [34] investigated the impact of some macroeconomic, individual, and business environment-related factors (GDP, GDP per capita, total tax rate, inflation rate, foreign direct investments, ease of access to finance, unemployment rate, fear of failure rate, entrepreneurial intentions, perceived capabilities, perceived opportunities, cost of business start-up procedures, time required to start a business, number of procedures needed for establishing a new firm) on the total entrepreneurial activity (TEA) rate in 18 European Union countries for a period of 14 years (2002-2015). The authors used three regression models and applied a panel data fixed effect model approach. The results of the study highlighted that the inflation rate, foreign direct investments, access to finance, and total tax rate are the main macroeconomic determinants of entrepreneurship.

In this study, the adequacy of regression models was assessed using the analysis of variance (ANOVA), which was has also been applied in other empirical studies $[31,55,56]$ and many others. The results of the regression analysis in a general form of two novel models are the following:

$$
\text { Model GD: GCI = f (DBI, Year), }
$$

$$
\text { Model GH: GCI = f (HDI, Year). }
$$

Linear regression models provide a rich and flexible framework that is applicable in many economic areas and issues. However, linear models are not suitable for all cases. There are many problems where dependent variables and independent variables (predictors) are linked through a known nonlinear function, which leads to the construction of a nonlinear regression model (NRM). In general, a non-linear model has the following form:

$$
Y=f(x, \boldsymbol{\theta})+\varepsilon,
$$

where $\theta$ is $\mathrm{k} \times 1$ of the unknown parameter vector and $\varepsilon$ is the uncorrelated random error with a zero mean value. Another prerequisite is a normal error distribution. Since the mean error value is zero:

$$
\boldsymbol{E}(\boldsymbol{Y})=E[f(x, \boldsymbol{\theta})+\varepsilon]
$$

then the function, $f(x, \theta)$, is the regression function of a nonlinear regression model. The values of individual regression coefficients can then be obtained by the least squares method formulated as:

$$
S(\boldsymbol{\theta})=\sum_{i=1}^{n}\left[y_{i}-f\left(x_{1}, \boldsymbol{\theta}\right)\right]^{2} .
$$

To find the least squares estimate, it is then necessary to differentiate this equation with respect to each component of the parameter, $\theta$, which leads to a system of normal equations for nonlinear regression. The normal equations then have the following form: 


$$
\sum_{i=1}^{n}\left[y_{i}-f\left(x_{i}, \theta\right)\right]\left[\frac{\partial f\left(x_{i}, \theta\right)}{\partial \theta_{j}}\right]_{(\theta=\hat{\theta})}=0,
$$

where $\mathrm{j}=1,2, \ldots, \mathrm{k}$ and where $\hat{\theta}$ is the estimate of the regression coefficient, $\theta$.

Based on the results of the GD (Equation (5)) and GH (Equation (6)) models, we designed the third GDH (Equation (14)) model to simultaneously reflect the non-linear relations among the dependent variable (GCI) and two independent variables (DBI and HDI). The GDH (Equation (14)) model is described in more detail in Section 4.3. Considering the availability of data, the intention of this paper was also to compare the real GCI 2018 score published in the Report of World Economic Forum and the quantified GCI 2018 score by means of the GD (Equation (5)) model using real DBI scores.

\section{Results}

The first partial analysis focused on the comparison of the average GCI, DBI, and HDI scores achieved by EU (28) countries during the years 2006 to 2017 in terms of the analyzed economic categories-global competitiveness, business environment, and human development (see Table 2). In the second partial analysis, attention was paid to the evaluation of the individual regression modelling results. In line with the performed analyses, the last partial analysis was focused on the verification of the designed models and prediction of the GCI score for 2018 on the basis of the DBI.

Table 2. Average values of the GCI, DBI, and HDI scores during the years 2006 to 2017. Source: own processing.

\begin{tabular}{|c|c|c|c|c|c|c|c|c|c|c|c|}
\hline \multirow{2}{*}{ Country } & \multicolumn{3}{|c|}{ Multi-Criteria Indices } & \multirow{2}{*}{ Country } & \multicolumn{3}{|c|}{ Multi-Criteria Indices } & \multirow{2}{*}{ Country } & \multicolumn{3}{|c|}{ Multi-Criteria Indices } \\
\hline & GCI & DBI & HDI & & GCI & DBI & HDI & & GCI & DBI & HDI \\
\hline AT & 74.02 & 76.83 & 89.32 & $\mathrm{DE}$ & 78.61 & 78.72 & 92.47 & PL & 63.40 & 68.29 & 83.89 \\
\hline $\mathrm{BE}$ & 73.92 & 72.02 & 90.55 & EL & 57.50 & 63.02 & 85.84 & PT & 63.92 & 72.70 & 82.76 \\
\hline BG & 60.00 & 68.73 & 78.59 & HU & 61.40 & 67.60 & 82.63 & RO & 59.35 & 67.15 & 79.63 \\
\hline HR & 58.93 & 62.96 & 81.40 & IE & 71.31 & 81.46 & 91.36 & SK & 61.14 & 70.47 & 83.49 \\
\hline CY & 61.91 & 68.62 & 85.43 & IT & 63.11 & 67.26 & 87.23 & SI & 62.95 & 66.18 & 88.27 \\
\hline $\mathrm{CZ}$ & 65.90 & 68.47 & 86.70 & LV & 62.10 & 74.93 & 82.75 & ES & 66.04 & 71.07 & 87.03 \\
\hline DK & 77.14 & 84.13 & 91.85 & LT & 63.83 & 75.31 & 83.58 & SE & 78.98 & 80.68 & 91.27 \\
\hline $\mathrm{EE}$ & 67.46 & 77.22 & 85.33 & LU & 72.48 & 66.59 & 89.24 & UK & 77.08 & 83.06 & 90.60 \\
\hline FI & 78.51 & 80.75 & 90.83 & MT & 62.94 & 63.51 & 84.88 & & & & \\
\hline FR & 73.66 & 71.04 & 88.66 & NL & 78.12 & 74.80 & 91.64 & & & & \\
\hline
\end{tabular}

\subsection{The Development Analysis of Selected Multi-Criteria Indices within the EU (28) Countries}

In order to assess the actual positions of the EU (28) countries, the initial analysis focused on the GCI, DBI, and HDI indices development over the years 2006 to 2017. Based on the average scores of the above mentioned multi-criteria indices, we analyzed the results achieved as well as the rankings of the EU (28) member states.

\subsubsection{The Development Analysis of the GCI within the EU (28) Countries}

Brief comments concerning the assessment of individual indices over the monitored period are presented in the text below, starting with the most common one, the GCI. Figure 1 graphically presents the average GCI score within all the member states of EU (28) in the period of 2006 to 2017.

Compared to other multi-criteria indices assessment, the lowest average values were recorded in the case of the GCI. Moreover, the most significant global competitiveness disparities among the EU (28) countries were identified since the GCI score range during the years of 2006 to 2017 reached the highest value of 27.15. According to the development of the GCI score for all member states, an increasing trend of the average values (from 66.73 to 69.60) was noted, representing a positive and desirable development. Over the period analyzed, the average GCI score within all EU (28) member states achieved the level of 67.70. The lowest GCI score in the period of 2006-2009 was recorded in 
the case of Bulgaria and since 2010, for Greece. In this context, the least competitive countries in the EU included Greece (57.50), Croatia (58.93), Romania (59.35), and Bulgaria (60.00). Finland ranked first in the four years (2006, 2012-2014), Denmark (2007-2008), Sweden (2009-2011), and Germany (2015). In the last two years of the analyzed period, two countries, Germany and the Netherlands, ranked first in the global competitiveness score. The best average GCI score was achieved in Sweden (78.98), and Finland achieved the highest GCI score (82.29) within the European area in 2006. Sweden, Germany, Finland, the Netherlands, Denmark, and the United Kingdom can also be ranked among the best-rated countries.

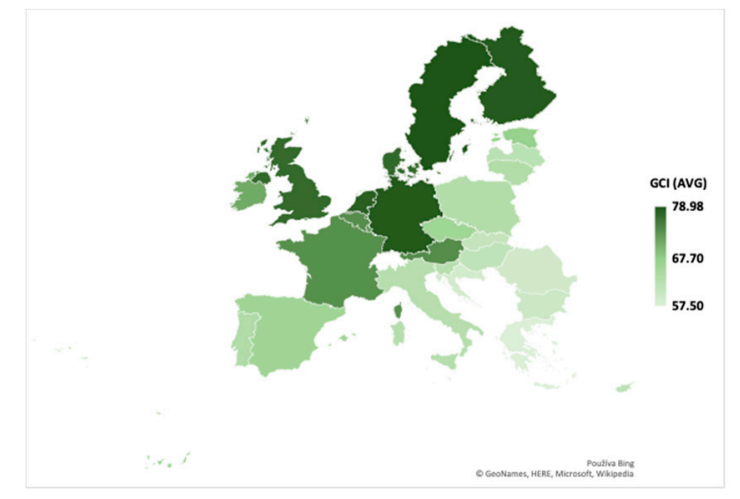

Figure 1. The average GCI score of EU (28) countries over the analyzed years, 2006-2017. Source: own processing.

\subsubsection{The Development Analysis of the DBI within the EU (28) Countries}

In the following partial analysis, we focused on the business environment assessment of the EU (28) member states by means of the DBI. Figure 2 below illustrates the average DBI score achieved during the analyzed years of 2006 to 2017.

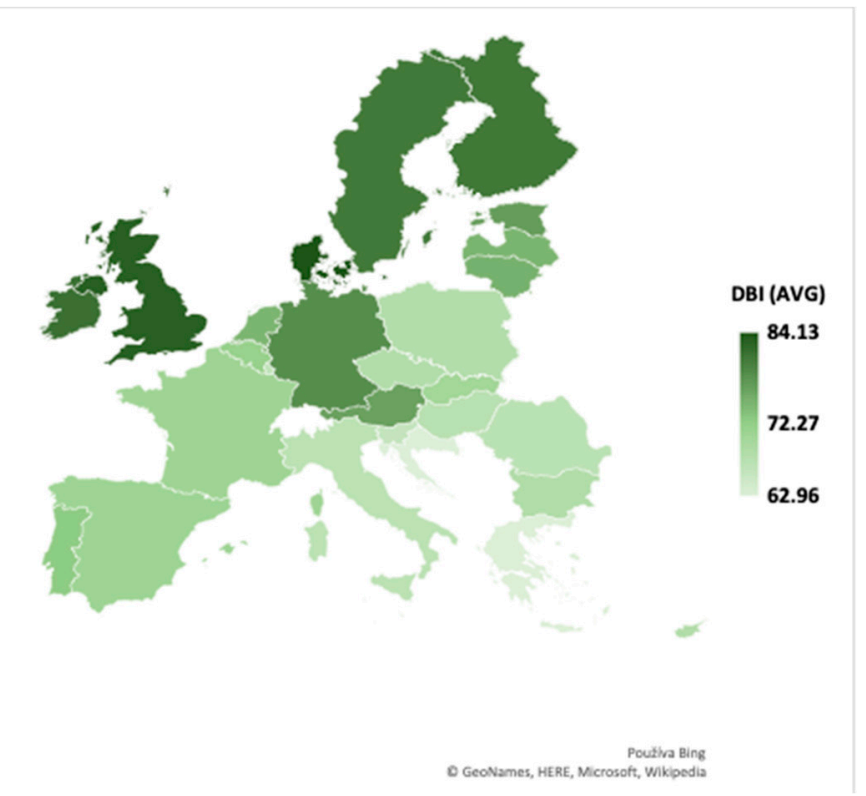

Figure 2. The average DBI score of EU (28) countries over the analyzed years, 2006-2017. Source: own processing.

The development of the average DBI score in all EU (28) countries showed a growing trend (from 68.50 to 76.38), except in 2017, when a slight decline was recorded. The average DBI score within the EU (28) countries attained a level of 72.27. Overall, the worst-rated countries in terms of the DBI 
were Croatia (2006-2009), Greece (2010-2012), and Malta (2013-2017), while vice-versa, Denmark has consistently achieved the best results since 2009 as well as Ireland (2006-2008). Based on the average results, the business environment was best evaluated in Denmark (84.13), Great Britain (83.06), Ireland (81.46), Finland (80.75), and Sweden (80.68). The least attractive business conditions except for Malta (63.51) were identified in the case of Greece (63.02) and Croatia (62.96).

\subsubsection{The Development Analysis of the HDI within the EU (28) Countries}

The last multi-criteria index subjected to the brief development analysis within all the EU (28) countries was the HDI. Figure 3 demonstrates the resulting HDI average score over the years of 2006 to 2017.

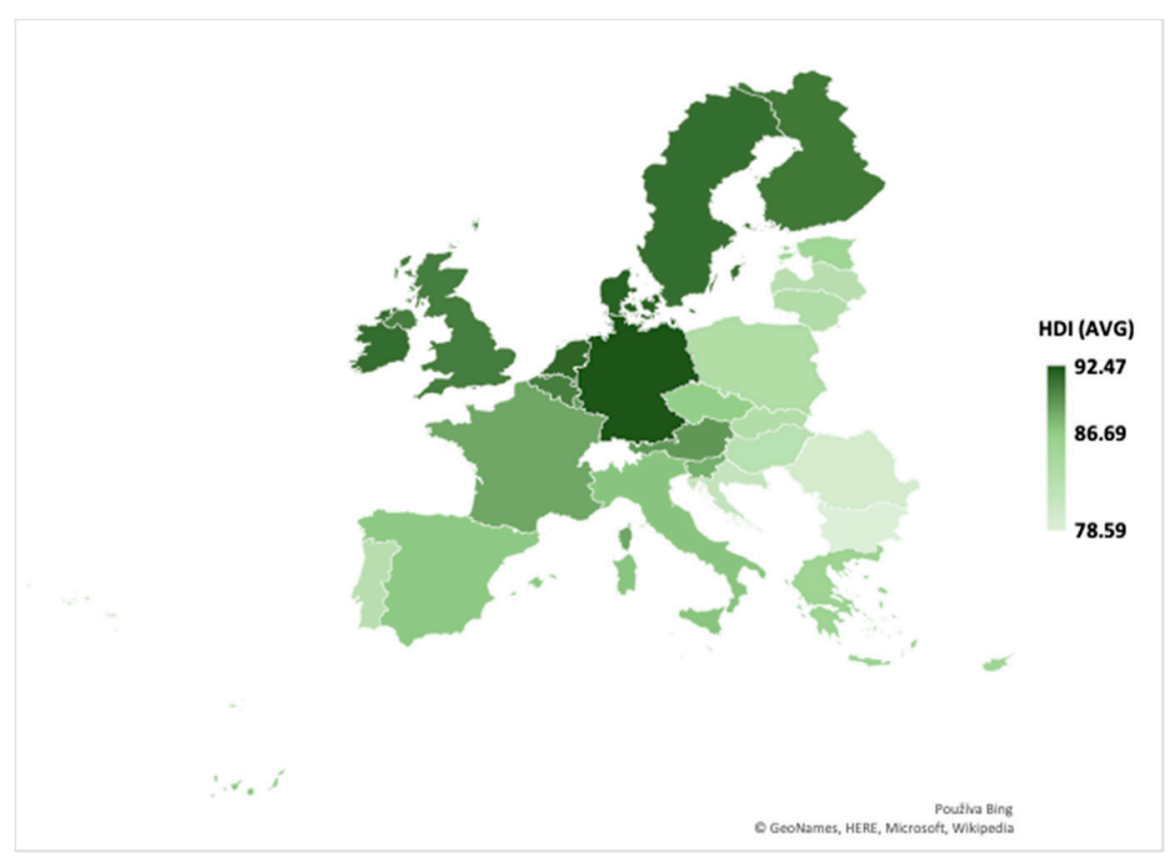

Figure 3. The average HDI score of EU (28) countries over the analyzed years, 2006-2017. Source: own processing.

Over the analyzed period, the average HDI score (within all the EU (28) countries evaluated) reached the highest values in comparison with the GCI and DBI. Besides that, all countries acquired a desirable growing trend of the average HDI score (from 84.84 to 88.38). Based on the comparative analysis of the DBI across the EU (28) countries, we can conclude that the lowest average value was achieved by Bulgaria (78.59), while vice-versa, the highest score was recorded by Germany (92.47). From all indices analyzed, the HDI scores achieved the lowest difference (13.88) between the best and the worst. This fact indicates that European countries are the most balanced within human development. Based on a comparative analysis across the EU, we can conclude that the overall lowest average HDI values were achieved for Bulgaria from 2006 to 2014. Although Romania's HDI was lower in 2015 to 2017 and during the analyzed years of 2006 to 2017, the average value was 79.63. In addition to these two countries, the development of human capital was also negatively evaluated for Croatia (81.40), Hungary (82.63), Latvia (82.75), and Portugal (82.76). On the other hand, with the exception of 2017, the highest HDI value was achieved by Germany (2006-2012, 2014-2016) and Denmark (2013). Currently, Ireland (93.8) is the leader in this area together with Germany, Sweden, the Netherlands, Denmark, Finland, and the United Kingdom. 


\subsection{The Results of the Panel Analysis and Regression Modeling}

The following partial analysis focused on an evaluation of the panel analysis and regression modeling results. As part of the regression model constructions, the GCI represented a dependent variable reflecting each country's global competitiveness and two independent variables were also included - the DBI and HDI.

\subsubsection{Results of the Panel Analysis}

The panel analysis was used to determine the relationship between the dependent variable (GCI) and the independent model variables represented by the DBI and HDI. Within the panel data analysis, we focused on time series analysis (2006-2017) on a sample of 28 European countries, which represented a set of 329 observations.

Based on the Hausman test, where the test statistic value reached $\mathrm{H}=93.0842$ and a significance level of $p=6.1238 \cdot 10^{-21}$, we can conclude that at the selected $5 \%$ level of significance, the null hypothesis of the Hausman test can be accepted and thus the random effects of the model are consistent in favor of the fixed effect model. To further analyze the panel data, we chose a fixed effect model (FEM).

The fixed effect model (FEM), unlike the combined regression model, assumes a diversity of cross-sectional units in absolute members.

The FEM model is:

$$
\mathbf{y}=\left[\begin{array}{c}
\mathbf{y}_{1} \\
\mathbf{y}_{2} \\
\cdot \\
\mathbf{y}_{n}
\end{array}\right]=\left[\begin{array}{cccc}
\mathbf{i} & \mathbf{0} & \ldots & \mathbf{0} \\
\mathbf{0} & \mathbf{i} & \ldots & \mathbf{0} \\
\cdot & \cdot & & \cdot \\
\mathbf{0} & \mathbf{0} & \ldots & \mathbf{i}
\end{array}\right]\left[\begin{array}{c}
\alpha_{1} \\
\alpha_{2} \\
\cdot \\
\alpha_{n}
\end{array}\right]+\left[\begin{array}{c}
\mathbf{x}_{1} \\
\mathbf{x}_{2} \\
\cdot \\
\mathbf{x}_{n}
\end{array}\right] \boldsymbol{\beta}+\left[\begin{array}{c}
\mathbf{u}_{1} \\
\mathbf{u}_{2} \\
\cdot \\
\mathbf{u}_{n}
\end{array}\right]=\mathbf{D} \boldsymbol{\alpha}+\mathbf{x} \boldsymbol{\beta}+\mathbf{u}
$$

We can see that in the model, the matrix columns, $\mathbf{D}$, represent artificial variables, $\mathbf{D}_{1}$ to $\mathbf{D}_{n}$, which are $d_{i t}=1$ for the $i$ cross-section unit, and $d_{i t}=0$ for all other cross-sectional units.

Based on the panel data and the results listed above, the basic features of the analyzed model were as follows:

- Model: Fixed-effects, using 329 observations.

- Included 28 cross-sectional units.

- Time-series length: Minimum 7, maximum 12.

- Dependent variable: GCI.

Table 3 shows that there is a direct linear relationship between the GCI and HDI. At the same time, the impact of the DBI on the change in the GCI value was not confirmed. Further results of the panel analysis can be summarized as follows: The average value of the investigated dependence of the GCI was 67.8305 with a standard deviation of 7.2166. The sum of the squares of the residues was 790.6613. The modified determination index as a measure of the model's ability to explain the change in the GCI variable of interest was $95.3714 \%$. The Fisher-Snedecor test criterion converted to a probability scale of $p=3 \cdot 0 \cdot 10^{-181}$ points to the fact that the selected fixed-coefficient model was adequate, and thus the predictors chosen (HDI and DBI) were suitable for describing the investigated GCI variable.

Table 3. Basic results of the panel analysis of the fixed coefficient model. Source: own processing.

\begin{tabular}{ccccc}
\hline & Coefficient & std. Error & t-ratio & $p$-value \\
\hline const & 46.7313 & 7.9008 & 5.9150 & $9.08 \cdot 10^{-9} *$ \\
DBI & -0.0411 & 0.0339 & -1.2110 & 0.2269 \\
HDI & 0.2775 & 0.1084 & 2.5600 & $0.0109 *$ \\
\hline
\end{tabular}

Note: * indicates significance level of $\alpha=0.05$. 
The difference between the individual cross-sectional units was tested by using the F-test, which compared the FEM model and the combined regression model, represented by:

$$
F=\frac{\left(R S S_{\text {pool }}-R S S_{F E M}\right) /(n-1)}{R S S_{F E M} /(n T-k-n)}
$$

We compared this with the table value, $\mathrm{F}(n-1, n T-k-n)$ at the chosen significance level, $\alpha$. If the statistics value was greater than the table value, we rejected the null hypothesis that cross-sectional units have the same absolute terms. Since the test statistics, F $(27,299)=55.6126$, converted to a probability scale reached $p=4.3622 \cdot 10^{-100}$, the null hypothesis of the equality of absolute members of cross-sectional units was rejected.

\subsubsection{The Results of Regression Modeling_GD Model}

When creating the first regression model (GD model), we focused on estimating the existence of a relation between the global competitiveness assessment (GCI) and business environment assessment (DBI) in the complex environment of EU (28) member states over the years 2006-2017.

The designed regression model GD (Equation (5)) assumes a statistically significant GCI dependency on the DBI change and individual year within the analyzed period, 2006-2017. Based on the essential parameters in the case of the GD model, the proportion of the GCI variability (RSquare) represented $48.5447 \%$ and the adjusted determination coefficient affecting the extent of the variability explanation of the analyzed data by the given model was $48.0697 \%$.

In accordance to analysis of variance (ANOVA), it can be stated that the variability caused by random errors was significantly lower than the variability of the measured values explained by the regression model. The achieved value of the significance level (Prob $>$ F) points to the adequacy of the above mentioned model, which was confirmed by the Fisher-Snedecor test criterion $(F=102.2052)$. The significance level achieved a value of 0.0001 , so it can be concluded that this model was adequate within the selected significance level, $\alpha=5 \%$. The assigned predictors explained the change of the examined multi-criteria index (GCI) in an appropriate manner.

In Table 4, estimates of the effect size of the individual variables of the GD (Equation (5)) regression model are presented, which indicates the impact of the predictors on the observed GCI change. Based on the analysis performed, it is evident that the DBI score, as well as its square number of this index, were significant factors. The intercept of the above-mentioned model was not statistically significant at the chosen significance level of $\alpha=5 \%$. In addition, the variable "Year" was modelled as a nominal variable and was not statistically significant either. Due to the statistical insignificance of the variable "Year" as a predictor, we removed this variable from the model. The results of this exclusion led to the validity of the created model in all analyzed years, 2006-2017. Moreover, the results presented in Table 4 indicate that the GCI score growth was determined by the DBI score increase.

Table 4. Parameter estimation—the GD model. Source: own processing.

\begin{tabular}{ccccccc}
\hline Term & Estimate & Std Error & t Ratio & Prob $>|\mathbf{t}|$ & Lower 95\% & Upper 95\% \\
\hline Intercept & 961.7739 & 183.7518 & 5.23 & $<0.0001{ }^{*}$ & 600.2809 & 1323.267 \\
\hline DBI & 0.7592 & 0.0434 & 17.49 & $<0.0001{ }^{*}$ & 0.6738 & 0.8445 \\
\hline$(\text { DBI-72.4261 })^{*}($ DBI-72.4261) & 0.0144 & 0.0049 & 2.91 & $0.0039 *$ & 0.0047 & 0.0241 \\
\hline Year & -0.4721 & 0.0918 & -5.14 & $<0.0001{ }^{*}$ & -0.6526 & -0.2915 \\
\hline \multicolumn{7}{r}{ Note: ${ }^{*}$ indicates significance level of $\alpha=0.05}$.
\end{tabular}

The prediction profile of the GD (Equation (5)) model illustrated in Figure 4 points to the finding that the dependency of the GCI in relation to the DBI is non-linear. This result was also confirmed by the parameter estimation presented in Table 4 . The course of dependency represents the quadratic 
function whose graph was a parabola. However, no local extreme was evident in the interval of the values examined.

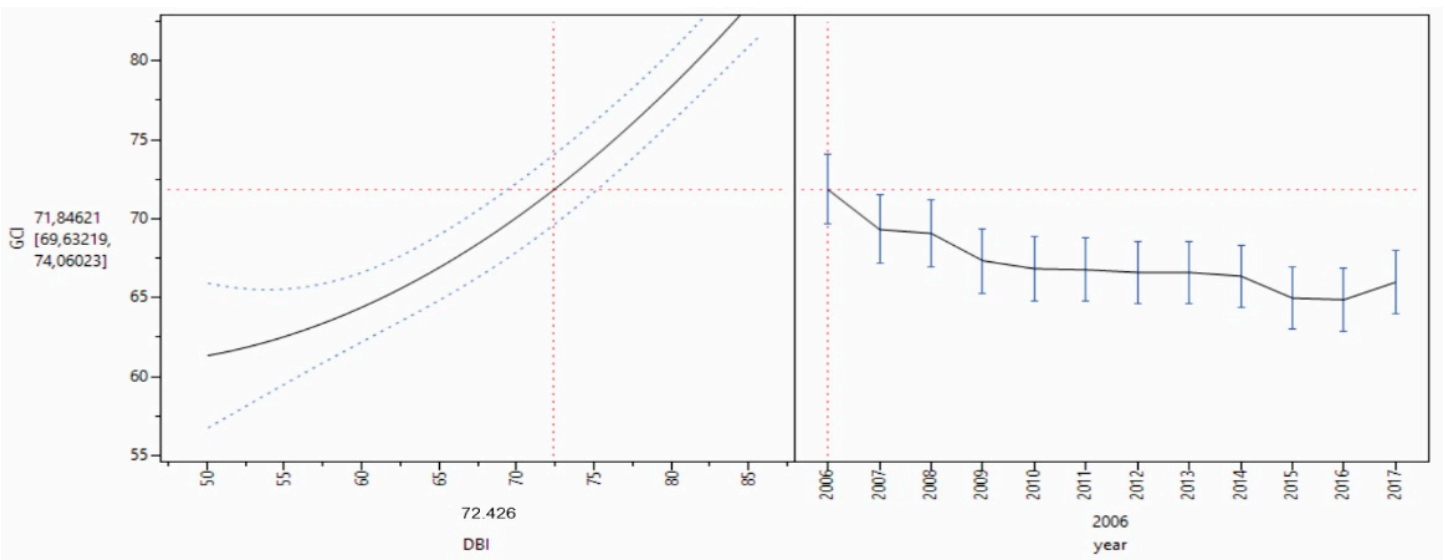

Figure 4. Visualization of the GD model prediction profile. Source: own processing.

In accordance to the parameter estimation within the GD model (Table 4 ) and taking into account the constant added to the model in order to deal with the non-orthogonality of the input data, the final prediction model has the following form:

$$
\text { GCI }=1037.3098-1.3267 \times \mathrm{DBI}-0.4721 \times \text { Year }+0.00144 \times \mathrm{DBI}^{2} .
$$

The residuals of predictive GD (Equation (12)) model are presented in Figure 5. The residuals quantified as the difference between the actual value of GCI and the GCI value calculated using the GD (Equation (12)) prediction model achieved a median equal to 0 . Despite the relatively low value of the adjusted determination coefficient, the residuals variance was quite significant. The residuals variance ranged from a minimum value of -10.7428 , up to the maximum value of +13.9593 . Therefore, the overall actual range of variance was 24.7021 .

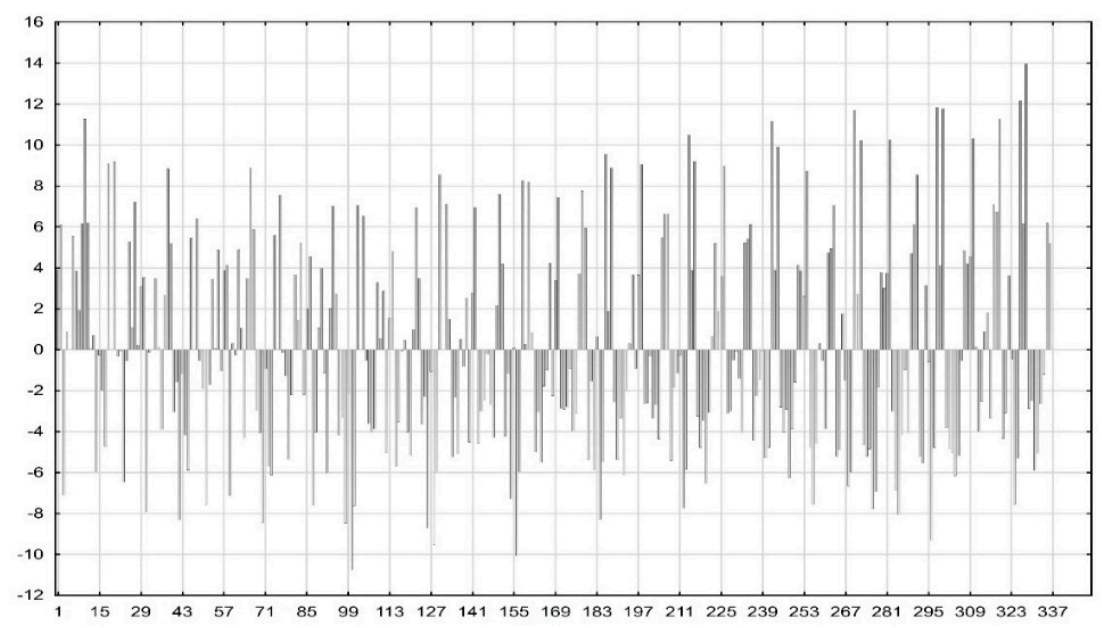

Figure 5. Visualization of the GD model residuals. Source: own processing.

Since the results of the non-linear regression were the basis for creating the GD model, a statistically significant relation between the GCI and DBI exists. Furthermore, at the significance level of $\alpha=5 \%$, we can conclude that the research hypothesis, H1, was confirmed. 


\subsubsection{The Results of Regression Modelling-GH Model}

When constructing the second regression model (GH model) for the period, 2006-2017, the attention was focused on detecting the relationship between the evaluation of the global competitiveness level (GCI) and human development (HDI) within the EU (28) member states.

The analyzed GH regression model assumed a statistically significant GCI dependency on the HDI change and individual year within the monitored period, 2006-2017. The GCI proportion of variability (RSquare) reached a level of $79.0178 \%$ and the adjusted determination coefficient reflecting the extent of data variability explained by the given model attained a value of $78.7642 \%$.

The results of the variance analysis (ANOVA) for the second analysis of the GH (Equation (6)) regression model indicate that the variability due to random errors was significantly lower than the variability of values explained by the GH (Equation (6)) regression model. The achieved level of significance (Prob $>$ F) points to the adequacy of this regression model based on the Fisher-Snedecor test criteria $(\mathrm{F}=311.6314)$. Since the significance level $(0.0001)$ was lower than the selected significance level of $\alpha=5 \%$, this model was considered as significant and suitable. In this regard, the HDI factor represents an adequate predictor for prognosticating the value of the GCI.

Table 5 presents estimates of the effect size of the individual variables of the GH (Equation (6)) regression model, which describes the predictors' impact on the analyzed response-the GCI. In line with the performed analysis, the HDI was identified as a significantly acting factor as well as the square number of this index. The absolute variable of the model was statistically significant within the selected significance level of $\alpha=5 \%$. However, the year modeled as a nominal variable was confirmed as insignificant. Due to the statistical insignificance of the year as a predictor, it was necessary to exclude it completely from this model. The consequence of this exclusion was the validity of the model in all analyzed years, 2006-2017. In addition, Table 5 indicates that the increasing HDI score caused the growth of the GCI score.

Table 5. Parameter estimation—the GH model. Source: own processing.

\begin{tabular}{ccccccc}
\hline Term & Estimate & Std Error & t Ratio & Prob $>|\mathbf{t}|$ & Lower 95\% & Upper 95\% \\
\hline Intercept & 821.8408 & 108.4057 & 7.58 & $<0.0001$ & 608.5899 & 1035.0917 \\
\hline HDI & 1.6929 & 0.0480 & 35.27 & $<0.0001$ & 1.5984 & 1.7873 \\
\hline Year & -0.4487 & 0.0544 & -8.25 & $<0.0001$ & -0.5557 & -0.3417 \\
\hline$($ HDI-86.6854) $\times($ HDI-86.6854) & 0.1146 & 0.0119 & 9.6 & $<0.0001$ & 0.0911 & 0.1381 \\
\hline$($ HDI-86.6854 $) \times($ Year-2011.5) & -0.0549 & 0.0150 & -3.66 & 0.0003 & -0.084 & -0.0253 \\
\hline
\end{tabular}

Figure 6, reflecting the prediction profile of the analyzed GH (Equation (6)) model, points to the same fact as Table 5 regarding the parameter estimation-the GCI dependency on the HDI change is non-linear. The course of dependence itself was expressed by a quadratic function, so a graphical representation of this function is a parabola. Figure 6 indicates that there is a local minimum of a function (approximately at the level of 80 of the HDI) in which the dependency changes from concave to convex. Increasing the HDI value to a local minimum caused a decrease in the GCI score. By contrast, exceeding the local minimum of the analyzed dependency resulted in a significant GCI increase.

Based on the result of Table 5 and considering the constant added to the model in order to deal with the non-orthogonality of the input data, the final prediction model was constructed as follows:

$$
\mathrm{GCI}=7889.4628+92.2481 \times \mathrm{HDI}+4.3103 \times \mathrm{Year}+0.1146 \times \mathrm{HDI}^{2} .
$$

The following Figure 7 illustrates the residuals of the GH (Equation (13)) predictive model. Residuals calculated as the difference between the real GCI value and the GCI value quantified by the GH (Equation (13)) model reached a mean of 0 . The minimum value was at the level of -8.7093 , 
while vice-versa, the maximum value was +10.2065 . Thus, the real deviation range reached the level of 18.9158 .

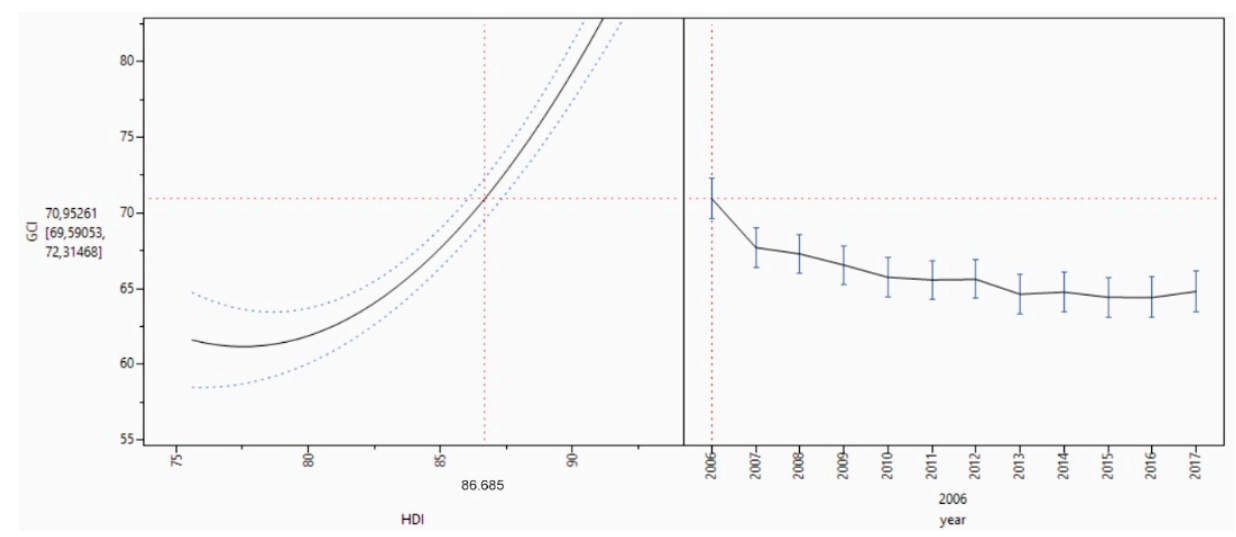

Figure 6. Visualization of the GH model prediction profile. Source: own processing.

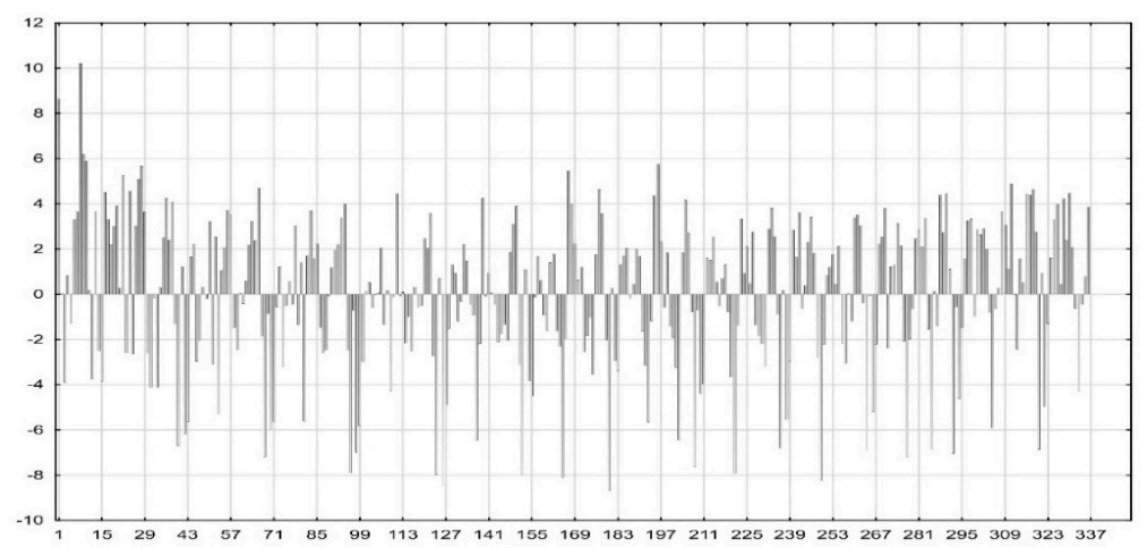

Figure 7. Visualization of the GD model residuals. Source: own processing.

Since the results of the non-linear regression represent a starting point for the creation of the GH model, we can state that there is a correlation between the GCI and HDI indices. In this regard, the research hypothesis, $\mathrm{H} 2$, was confirmed at the significance level of $\alpha=5 \%$.

\subsection{The Results of Regression Modelling-GDH Model}

Based on the results of the previous non-linear regression analysis, we proceeded to create the third regression model-the GDH model. In this case, the model consisted of one dependent variable (GCI score) and two independent variables represented by the indices, the DBI and HDI. The GDH model was aimed at detecting the existence of relations among the global competitiveness assessment (GCI) and the impact of two indices at the same time.

The analysis of relations within the third model in the context of the GCI, DBI, and HDI was based on the following general relation:

$$
\text { Model GDH: GCI = f (DBI, HDI, Year). }
$$

Based on the essential parameters results achieved, it is obvious that that the proportion of the variability of the examined GCI (RSquare) represented $87.5091 \%$ and the adjusted determination coefficient affecting the extent of the variability explanation of the selected data by the given model achieved a value of $87.1163 \%$.

The analysis of variance (ANOVA) results showed that the variability caused by random errors was significantly lower than the variability of measured values explained by the regression model. 
The achieved value of the significance level (Prob > F) points to the adequacy of the model used based on the Fisher-Snedecor test criterion $(\mathrm{F}=222.7846)$. The significance level achieved a value at 0.0001 , so it can be concluded that the model was adequate at the chosen significance level of $\alpha=5 \%$. In this regard, the assigned predictors were adequate for prognosticating the value of GCI.

The quantified estimates of the effect size of the individual variables in the regression model, GDH (Equation (14)), are presented in Table 6. Moreover, from the performed analysis, it is evident that the indices, HDI and DBI, are considered to be significantly effecting factors, but the variable "year" is not. At the significance level if $\alpha=5 \%$, the interaction of the HDI and DBI indices was statistically significant as well as the square number of these indices. The change of the GCI score was also determined to be significant by the square interaction of the HDI and DBI indices, as well as by the square interaction of the HDI and the individual year. In addition, from the analysis, it is evident that the HDI (expressed by main effect) had the most significant impact on the GCI score change.

Table 6. Parameter estimation—the GDH model. Source: own processing.

\begin{tabular}{|c|c|c|c|c|c|c|}
\hline Term & Estimate & Std Error & $t$ Ratio & Prob $>|t|$ & Lower $95 \%$ & Upper $95 \%$ \\
\hline Intercept & 2213.2239 & 154.3972 & 14.33 & $<0.0001 *$ & 1909.4549 & 2516.9929 \\
\hline HDI & 1.7170 & 0.0731 & 23.48 & $<0.0001$ * & 1.5732 & 1.8609 \\
\hline Year & -1.1579 & 0.0779 & -14.85 & $<0.0001 *$ & -1.3113 & -1.0044 \\
\hline DBI & 0.4623 & 0.0358 & 12.92 & $<0.0001$ * & 0.3919 & 0.5327 \\
\hline$($ HDI-86.7565) $\times($ HDI-86.7565) & 0.0718 & 0.0128 & 5.6 & $<0.0001 *$ & 0.0466 & 0.09708 \\
\hline$($ Year-2011.58) $\times($ Year-2011.58) & 0.0733 & 0.0142 & 5.14 & $<0.0001$ * & 0.0452 & 0.1013 \\
\hline$(\mathrm{HDI}-86.7565) \times(\mathrm{DBI}-72.4261)$ & -0.0225 & 0.0087 & -2.59 & $0.01 *$ & -0.0396 & -0.0054 \\
\hline$($ HDI-86.7565) $\times($ HDI-86.7565) $\times($ Year-2011.58) & 0.0357 & 0.0039 & 9.27 & $<0.0001 *$ & 0.0281 & 0.0433 \\
\hline$($ HDI-86.7565) $\times($ year-2011.58) $\times($ Year-2011.58 $)$ & -0.0146 & 0.0039 & -3.67 & $0.0003 *$ & -0.0224 & -0.0068 \\
\hline$(\mathrm{HDI}-86.7565) \times(\mathrm{HDI}-86.7565) \times(\mathrm{DBI}-72.4261)$ & -0.0181 & 0.0021 & -8.56 & $<0.0001 *$ & -0.0223 & -0.0139 \\
\hline$($ Year-2011.58) $\times($ DBI-72.4261 $) \times($ DBI-72.4261 $)$ & 0.0026 & 0.0008 & 3.39 & $0.0008^{*}$ & 0.0011 & 0.0042 \\
\hline
\end{tabular}

Note: * indicates significance level of $\alpha=0.05$.

The prediction profile of the analyzed model, GDH, listed in Figure 8 points to the finding that the dependence of the GCI on the DBI and HDI indices, as well as, on the "year" variable, is non-linear. The parameter estimation analysis (Table 6) confirms the mentioned findings. The course of dependency of the HDI and DBI indices represented the quadratic function whose graph is a parabola. Furthermore, Figure 8 shows that there was a local minimum of the function, whereby the dependency changes from concave to convex. However, no local extreme was evident in the interval of the values examined. The impact of the HDI on the change of the GCI score was expressed as parabola, as in the previous cases. This local minimum of the HDI score was about 72. Increasing the HDI score to the local minimum value caused a decrease of the GCI score. However, the local minimum value, which over fulfilled the dependency examined, led to significant increase of the GCI score. Based on the impact of the input variable "year" as the last predictor modelled, we found that increasing the variable "year" led to a decrease of the GCI score.

In accordance to the parameter estimation in the GDH model (Table 6) and taking into account the constant that was added to the model in order to deal with the non-orthogonality of the input data, the final prediction model has the following form:

$$
\begin{aligned}
& \mathrm{GCI}=4578335.381-4823.4395 \times \text { Year }+0.0026 \times \mathrm{DBI}^{2} \times \text { Year }-5.3265 \times \mathrm{DBI}^{2}- \\
& 0.0181 \times \mathrm{HDI}^{2}+3.1177 \times \mathrm{DBI} \times \mathrm{HDI}-0.3836 \times \mathrm{DBI} \times \mathrm{Year}+637.7491 \times \mathrm{DBI}+0.0357 \times \mathrm{HDI}^{2} \\
& \times \text { Year }-70.4618 \times \mathrm{HDI}^{2}-0.0146 \times \mathrm{HDI} \times \mathrm{Year}^{2}+52.6457 \times \mathrm{HDI} \times \text { Year }+1.3422 \times \mathrm{Year}^{2}
\end{aligned}
$$

The residuals of the GDH (Equation (15)) predictive model are shown in Figure 9. The residuals quantified as the difference between the actual value of the GCI and the GCI value calculated using the GDH (Equation (15)) prediction model achieved a median equal to 0 . The overall actual variance range 
achieved a value at the level of 13.3935. In this regard, the residuals' variance ranged from a minimum value of -8.4163 up to the maximum value of +5.2473 .

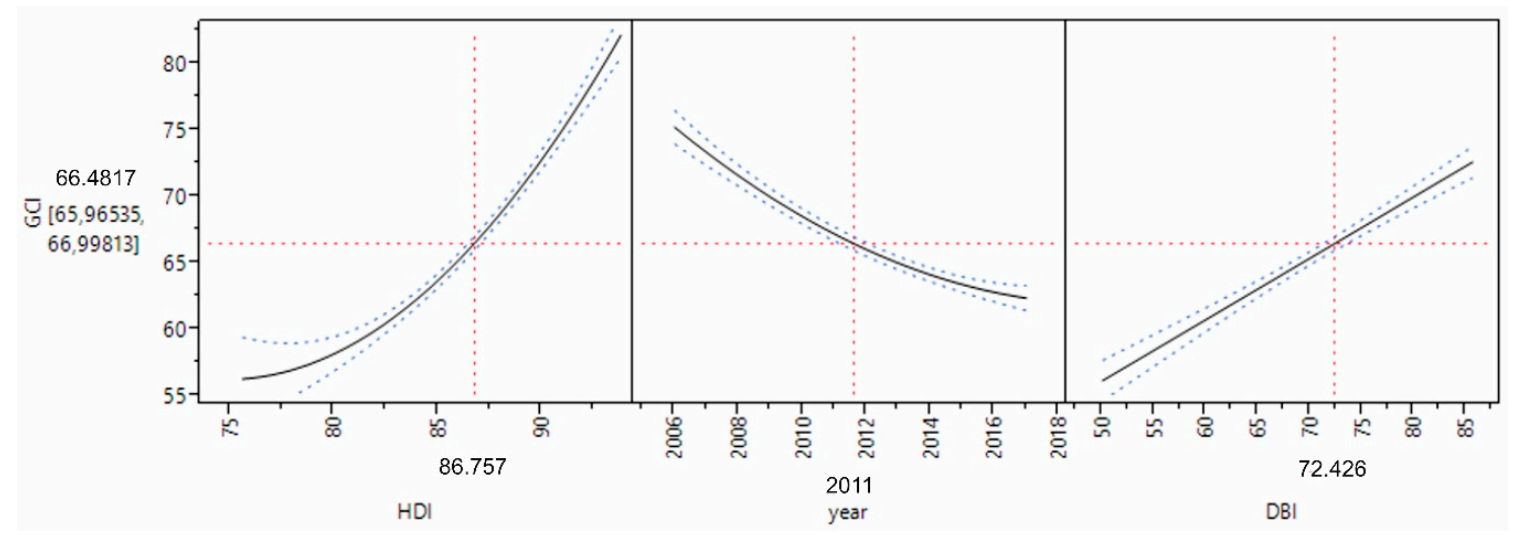

Figure 8. Visualization of the GH model prediction profile. Source: own processing.

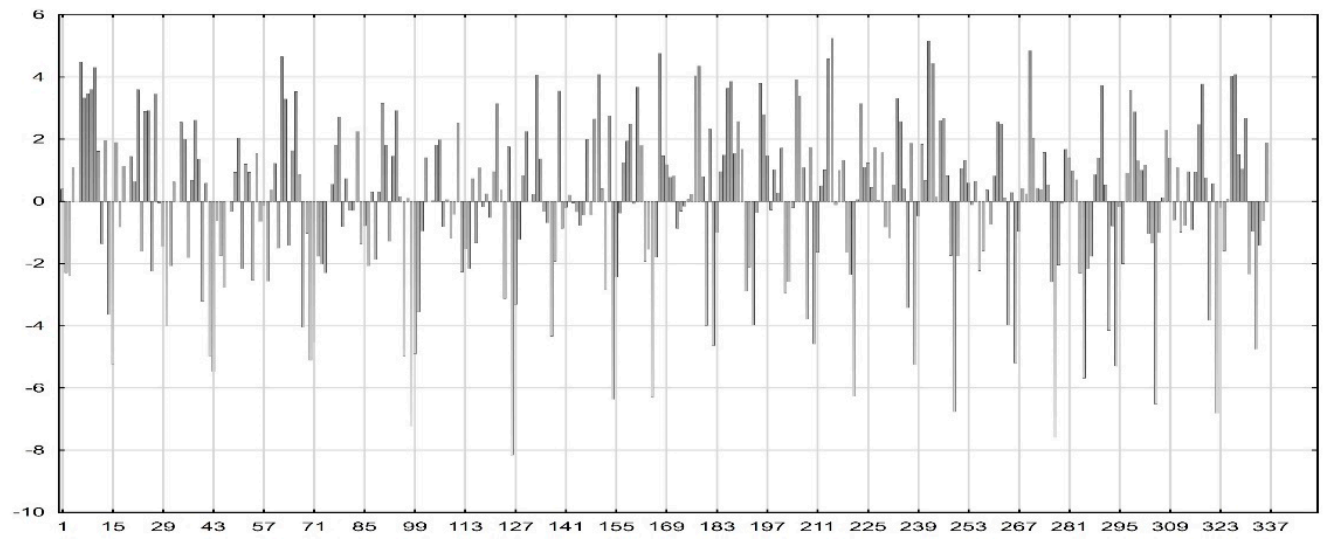

Figure 9. Visualization of the GDH model residuals. Source: own processing.

The last partial analysis focused on the GDH model creation point out that the interrelations among the global indexes examined were not linear. Individual global indices acting as independent variables within the GDH model affected the GCI score change non-linearly. It is also important to point out the significant effect of the interactions of independent variables. In addition, the year in which the index was evaluated played a major role in predicting the GCI score. However, these conclusions offer the opportunity for a deeper analysis of individual global indices and a detection of the causes of non-linearity and their interactions.

\subsection{The Verification of the Regression Models}

Based on the results of the previous non-linear regression analysis, we focused on the verification of the GD (Equation (12)) and GH (Equation (13)) model. Given the unavailability of the HDI scores for 2018, this verification analysis was only performed for the GD model (Equation (12)). Our intention was to predict the GCI 2018 score based on the (real) available DBI scores and then compare the difference between the calculated GCI 2018 score and the GCI score published in World Economic Forum 2018 report. The following Figure 10 graphically presents the GD (Equation (12)) model verification and the GCI score prediction for 2018. 


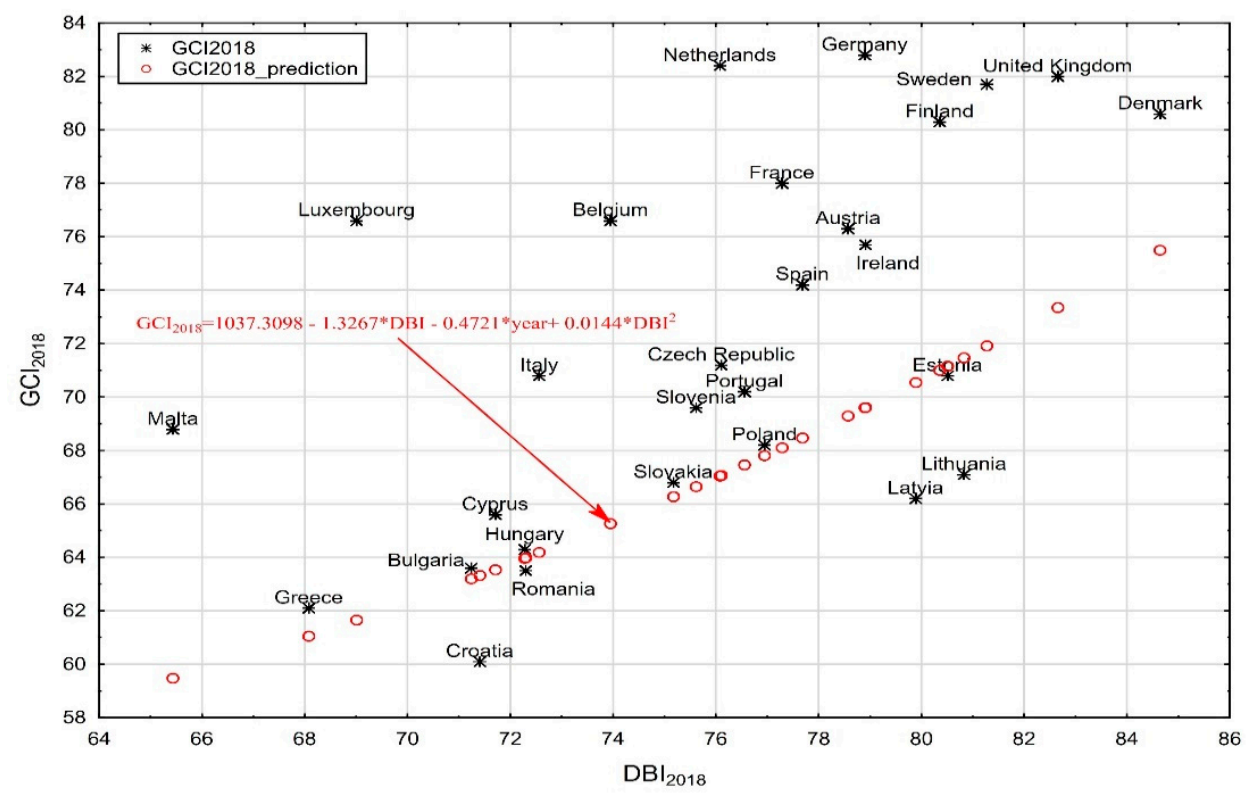

Figure 10. Verification of the GD (Equation (7)) model and prediction for 2018. Source: own processing.

Due to the GCI and DBI data availability for 2018, the proposed GD model for this particular year was verified. Despite the fact that mathematical statistical models were valid only in the range of values used in their construction, the GD model verification reached an average deviation of quantified and real values at the level of $6.1236 \%$. The minimum deviation was calculated for Estonia $(0.4994 \%)$, while the maximum deviation was found for Luxembourg (19.5141\%). In this regard, the result achieved can be considered acceptable. However, due to the complexity of the GDH model, its application in 2018 would result in a significantly lower deviation.

\section{Discussion}

In general, few research studies have been devoted to an assessment of the global competitiveness of countries in relation to other multi-criteria indices. Globally known organizations evaluate countries annually according to different criteria or aspects. Based on the data available, authors have focused on the assessment of competitiveness, business, or innovation environment from different perspectives using various indices or indicators (see the literature review). However, an examination of the interrelations among various indices using regression modelling has not been analyzed yet.

As an example, a multi-criteria assessment of the business environment within the selected countries was provided by [57]. The authors selected four different types of indices related to the business environment-the KOF ("Konjunkturforschungsstelle" = the German word, meaning Economic cycle research institute) index of globalization, the corruption perception index, the global innovation index, and the GCI-in order to compare results with average values over the European Union. In the research study, benchmarking and factor analysis was employed to identify and compare factors of business development. Multi-criteria analysis of sustainable socio-economic growth and development was addressed by [58]. The HDI was used as an indicator for human development, while the gross domestic product (GDP) was used as an indicator to reflect economic growth. Although the results showed that economic growth has a negative short term relationship with the HDI, the result was not significant. However, the coefficient for the long term relationship was significant. The findings confirmed that economic growth leads to human development, and macroeconomic policies aimed at achieving sustainable economic growth should be maintained. Another perspective for global competitiveness assessment was presented by [59]. The author assessed competitiveness based on innovation and investment in human capital in relation to unemployment and economic growth. The approach, based on panel vector-autoregressive models, indicated a lack of labor productivity and investment in human 
capital in order to decrease unemployment and increase economic growth. In regard to competitiveness, the paper [60] tested the relations between the GCI and economic growth rate by means of panel Granger causality analysis based on the annual data for 114 countries divided into five groups by income criteria for the period of 2006 to 2014 . The results confirmed a strong unidirectional causality between the indicators analyzed, i.e., GDP growth causes global competitiveness. Additionally, the authors found that the GCI was not successful in predicting economic growth.

The panel analysis results suggest that there is a direct linear relationship between the GCI and HDI. Moreover, the impact of the DBI on the change in the GCI score was not confirmed.

In our study, the regression models, GD (Equation (12)), GH (Equation (13)), and GDH (Equation (15)), point to the fact that the analyzed interrelations among the GCI (as dependent variable) and the DBI and HDI (as independent variables) are nonlinear. The application of nonlinear regression analysis led us to this conclusion and also revealed an interesting result. Based on the analysis, it was revealed that the real dependence among the analyzed indices shows some local minima, and after they were exceeded, the GCI score increased parabolically, depending on the DBI and HDI score increase. In addition to the above, the complex regression model, GDH (Equation (15)), also detected the mutual influence of the interaction of the DBI and HDI on the GCI score change. Therefore, the undisputed benefit of the resulting prediction model is uncovering deeper connections between the effects of the DBI and HDI on the overall GCI score change, as well as designing a computational model for predicting the GCI score with an average error at the level of $14 \%$. In this regard, verification of the regression model (Equation (15)) on 2018 data pointed to its validity with an average deviation of $3.597 \%$.

\section{Conclusions}

Economic prosperity and sustainable economic growth can be achieved by increasing competitiveness and creating a favorable business environment, while preserving a sufficient level of socio-economic cohesion. All the above-mentioned components are closely linked. Taking into account the overall results, we came to the conclusion that the business sector represents a key role in the process of sustainable economic development, for the reason that business activities are realized by human resources and contribute to a considerable improvement of competitiveness. A stable social market economy, environmentally-friendly economic development, and an enhancement of competitiveness lead to sustainable business strategies. We identified the main areas of countries' interests by creating three novel models with a combination of three indices-the GCI, DBI, and HDI. Our findings are important for policy decision-making processes and to attract investors with new technologies and innovation activities.

Globalization, growing international competitiveness, dynamic development of information and communications technology, growing role of knowledge, demographic problems, and shortages of resources, at the turn of the 19th and 2oth centuries, created great challenges for the European Union [61]. These circumstances have increased competition and forced all economies to pay more attention to international competitiveness, business conditions, and sustainable economic development. Today's Europe seeks smart, inclusive, and environmentally economic growth. This fact is also highlighted by [62], who consider the growth of the European Union as a combination of intelligent growth, sustainable growth, and growth-supporting integration. Moreover, one of the most urgent economic and managerial issues is, according to [63], the formation of a high level of competitive human capital of countries as well as ensuring high level rankings of global competitiveness.

As reported in the Annual Report on European SMEs 2017/18 [64], EU (28) SMEs made a significant contribution to the recovery and subsequent expansion of the European economy. They accounted for $47 \%$ of the total increase from 2008 to 2017 in the value added generated by the non-financial business sector, and for $52 \%$ of the cumulative increase in employment in the sector. In fact, their contribution exceeded what would have been expected based on their relative importance in the economy. The number of SMEs in the EU (28) increased by $13.8 \%$ between 2008 and 2017. Overall, 
in 2017, SMEs in the EU (28) non-financial business sector accounted for almost all EU-28 non-financial business sector enterprises (99.8\%), about $66.4 \%$ of the total EU (28) employment, and slightly less than three-fifths $(56.8 \%)$ of the value added generated by the non-financial business sector. Based on our research results, a significant impact of business environments and human capital on the position of EU (28) countries within global competitiveness rankings was confirmed. As SMEs account for more than $90 \%$ of the total number of EU(28) enterprises and two-thirds of the total EU (28) employment, with the expected continuation of this strong recovery of European SMEs, we see the potential in developing this business sector, which is considered an important driver of the recent growth and competitiveness of many European SMEs.

To survive in the current competitive and unpredictable business environment, it is significant for firms to search and enforce capabilities that lead them to adapt and cope with the dynamic changes of the environment for their sustainability [65].

However, our findings also have some limitations. The data unavailability in the case of the HDI score for 2018 can be considered as one of the main research limitations, since it was not possible to verify the GH (Equation (13)) model and subsequently predict the GCI score for 2018. We assume that increasing the complexity of a new prediction model by including the HDI would reduce the deviations and contribute to an improvement of the model's predictive ability. In view of the economic disparities and various political conditions for sustainable development, it is difficult to state whether the paper results were valid for all countries analyzed. Therefore, it would be interesting to verify the regression models created for each country. We consider the assessment of European countries via the overall GCI, DBI, and HDI scores as insufficient to understanding important and often hidden interrelations and factors influencing the countries' overall potential. For future research, a deeper analysis of these indices is recommended. The analysis of indices should explore linkings and dependencies of individual pillars and indicators on the evaluation of global competitiveness and prosperity. In the case of the GCI, attention should be focused on investigating 12 pillars and 114 indicators, the DBI should be analyzed through 10 dimensions and 45 indicators, and the HDI should be examined through 3 dimensions and 4 indicators. Moreover, since the current study was concentrated on only the selected multi-criteria indices, future investigations should integrate more diverse economic, social, and innovation areas and aspects (in the form of other multi-criteria indices) to analyze the growth potential of individual countries thoroughly. In our opinion, analysis should be extended to two other indices, namely the global innovation index (GII) and the economic freedom index (EFI).

Author Contributions: Conceptualization, D.K. and B.̌̌s; Data curation, V.Č. and E.O.; Formal analysis, B.̌̌., M.G., V.Č. and E.O.; Investigation, D.K., B.Š., V.Č. and E.O.; Methodology, B.Š. and M.G.; Project administration, D.K.; Resources, V.C. and E.O.; Supervision, D.K.; Validation, D.K. and M.G.; Visualization, B.S.; Writing—original draft, D.K., B.Š. and E.O.; Writing-review and editing, D.K., B.Š. and V.Č.

Funding: This work was supported by the Slovak Research and Development Agency under the contract No. APVV-15-0322 Competitiveness, economic growth and firm survival and VEGA 1/0279/19 Model approaches to increase performance and competitiveness in the European area in context of sustainable development.

Conflicts of Interest: The authors declare no conflict of interest. The funders had no role in the design of the study; in the collection, analyses, or interpretation of data; in the writing of the manuscript, or in the decision to publish the results.

\section{References}

1. Dima, A.M.; Begu, L.; Vasilescu, M.D.; Maassen, M.A. The Relationship between the Knowledge Economy and Global Competitiveness in the European Union. Sustainability 2018, 10, 1706. [CrossRef]

2. Bock, K. European Competitiveness and Industry; ERT Competitiveness Working Group. 2017, pp. 1-46. Available online: http://ert-industry-benchmarking.eu/wp-content/uploads/2017/12/ERT-Stats_Benchmarking-2017_ 4web_21122017hyperlinksgroupedBookmarks.pdf (accessed on 15 January 2019).

3. Hoyer, W. Restoring EU Competitiveness; European Investment Bank. 2016, pp. 1-52. Available online: https://www.eib.org/attachments/efs/restoring_eu_competitiveness_en.pdf (accessed on 12 February 2019). 
4. Voinescu, R.; Moisoiu, C. Competitiveness, Theoretical and Policy Approaches. Towards a More Competitive EU. Procedia Econ. Financ. 2015, 22, 512-521. [CrossRef]

5. Tudose, M.B.; Rusu, V.D. Global Competitiveness of the European Union Member States: Evolution and Perspectives. Stud. Sci. Res. Econ. Ed. 2015, 22, 23-31. [CrossRef]

6. Kiseláková, D.; Šofranková, B.; Čabinová, V.; Onuferová, E. Competitiveness and Sustainable Growth Analysis of the EU Countries with the Use of Global Indexes' Methodology. Entrep. Sustain. Issues 2018, 5 , 581-599. [CrossRef]

7. Huang, G.; Jiang, Y. Urbanization and Socioeconomic Development in Inner Mongolia in 2000 and 2010: A GIS Analysis. Sustainability 2017, 9, 235. [CrossRef]

8. Socol, C.; Marinas, M.; Socol, A.G.; Armeanu, D. Fiscal Adjustment Programs versus Socially Sustainable Competitiveness in EU Countries. Sustainability 2018, 10, 3390. [CrossRef]

9. Petryle, V. Does the Global Competitiveness Index Demonstrate the Resilience of Countries to Economic Crisis? Ekonomika 2016, 95, 28-36. [CrossRef]

10. Schwab, K. The Global Competitiveness Report; World Economic Forum, 2018; pp. 1-671. Available online: http: //www3.weforum.org/docs/GCR2018/05FullReport/TheGlobalCompetitivenessReport2018.pdf (accessed on 14 January 2019).

11. Dudas, T.; Cibula, A. The Changing Methodology of the Global Competitiveness Index and Its Impact on Slovakia. AD ALTA J. Interdiscip. Res. 2018, 8, 50-53.

12. Roy, S. Impact of Competitiveness Drivers on Global Competitiveness Index. Pac. Bus. Rev. Int. 2018, 11, $17-29$.

13. Stanickova, M. Classifying the EU Competitiveness Factors Using Multivariate Statistical Methods. Procedia Econ. Financ. 2015, 23, 313-320. [CrossRef]

14. Bucher, S. The Global Competitiveness Index as an Indicator of Sustainable Development. Her. Russ. Acad. Sci. 2018, 88, 44-57. [CrossRef]

15. Januškaitè, V.; Užienè, L. Intellectual Capital as a Factor of Sustainable Regional Competitiveness. Sustainability 2018, 10, 4848. [CrossRef]

16. Sadaf, R.; Oláh, J.; Popp, J.; Máté, D. An Investigation of the Influence of the Worldwide Governance and Competitiveness on Accounting Fraud Cases: A Cross-Country Perspective. Sustainability 2018, 10, 588. [CrossRef]

17. Hussain, M.E.; Haque, M. Impact of Economic Freedom on the Growth Rate: A Panel Data Analysis. Economies 2016, 4, 5. [CrossRef]

18. Pohludka, M.; Stverkova, H.; Ślusarczyk, B. Implementation and Unification of the ERP System in a Global Company as a Strategic Decision for Sustainable Entrepreneurship. Sustainability 2018, 10, 2916. [CrossRef]

19. Fiala, R. Testing Convergence toward Gibrat's Law for Czech Manufacturing Firms. Ekonomický časopis 2017, 65, 737-750.

20. Gallo, P.; Mihalcova, B.; Timkova, V.; Tomcikova, L. Importance of Financial and Non-financial Indicators in Companies with the Balanced Scorecard Concept. Qual. Access Success 2018, 19, 34-38.

21. Goergieva, K. Doing Business 2018-Reforming to Create Jobs. In A World Bank Group Flagship Report; World Bank Group: Washington, DC, USA, 2018; Volume 15, pp. 1-312.

22. Komarova, V.; Lonska, J.; Lavrienenko, O.; Menshikov, V. Influence of Existing Social and Economic Interactions on Sustainable Territory Development: The Case of Iceland. Entrep. Sustain. Issues 2018, 5, 412-437. [CrossRef]

23. Lehmann, T.; Benner, M. Cluster Policy in the Light of Institutional Context-A Comparative Study of Transition Countries. Adm. Sci. 2015, 5, 188-212. [CrossRef]

24. Kot, S. Sustainable Supply Chain Management in Small and Medium Enterprises. Sustainability 2018, 10, 1143. [CrossRef]

25. Pietrasieński, P.; Ślusarczyk, B. Internationalization of Small and Medium Enterprises—Empirical Research Review on Barriers to Entry into Foreign Markets. Pol. J. Manag. Stud. 2015, 11, 113-123.

26. Korcsmaros, E.; Simova, M. Factors Affecting the Business environment of SMEs in Nitra Region in Slovakia. Oeconomia Copernicana 2018, 9, 309-331. [CrossRef]

27. Kozubikova, L.; Homolka, L.; Kristalas, D. The Effect of Business Environment and Entrepreneurs' Gender on Perception of Financial Risk in the SMSs Sector. J. Compet. 2017, 9, 36-50. [CrossRef] 
28. Zygmunt, J. Entrepreneurial Activity Drivers in the Transition Economies. Evidence from The Visegrad Countries. Equilib. Q. J. Econ. Econ. Policy 2018, 13, 89-103. [CrossRef]

29. Kot, S.; Goldbach, I.R.; Slusarczyk, B. Supply Chain Management in SMEs-Polish and Romanian Approach. Econ. Sociol. 2018, 11, 142-156. [CrossRef]

30. Rajnoha, R.; Stefko, R.; Merkova, M.; Dobrovic, J. Business Intelligence as a Key Information and Knowledge Tool for Strategic Business Performance Management. E \& M Ekon. Manag. 2016, 19, 183-203. [CrossRef]

31. Ślusarczyk, B.; Grondys, K. The Concept of Sustainable Development in the Functioning of Municipalities Belonging to Special Economic Zones in Poland. Sustainability 2018, 10, 2169. [CrossRef]

32. Sun, W.; Pang, J. Service Quality and Global Competitiveness: Evidence from Global Service Firms. J. Serv. Theory Pract. 2017, 27, 1058-1080. [CrossRef]

33. Hossain, M.T.; Hassan, Z.; Shafiq, S.; Basit, A. Ease of Doing Business and Its Impact on Inward FDI. Indones. J. Manag. Bus. Econ. 2018, 1, 52-65. [CrossRef]

34. Rusu, V.D.; Roman, A. Entrepreneurial Activity in the EU: An Empirical Evaluation of Its Determinants. Sustainability 2017, 9, 1679. [CrossRef]

35. Wang, C.N.; Le, A.P. Application in International Market Selection for the Export of Goods: A Case Study in Vietnam. Sustainability 2018, 10, 4621. [CrossRef]

36. Dhir, S.; Ongsakul, V.; Ahmed, Z.U.; Rajan, R. Integration of Knowledge and Enhancing Competitiveness: A Case of Acquisition of Zain by Bharti Airtel. J. Bus. Res. 2019. [CrossRef]

37. Fabus, M. Business Environment Analysis Based on the Global Competitiveness Index (GCI) and Doing Business (DB): Case study Slovakia. J. Secur. Sustain. Issues 2018, 7, 831-839. [CrossRef]

38. Zhou, G.; Gong, K.; Luo, S.; Xu, G. Inclusive Finance, Human Capital and Regional Economic Growth in China. Sustainability 2018, 10, 1194. [CrossRef]

39. Ștefănescu-Mihăilă, R.O. Social Investment, Economic Growth and Labor Market Performance: Case Study-Romania. Sustainability 2015, 7, 2961-2979. [CrossRef]

40. Jahan, S. Human Development Indices and Indicators; United Nations Development Programme: New York, NY, USA, 2018.

41. Yang, F.; Pan, S.; Yao, X. Regional Convergence and Sustainable Development in China. Sustainability 2016, 8 , 121. [CrossRef]

42. Aguiar, A.; Tome, M.A.; Farias, A.D.; Machado, C.; Ribeiro, D.N.M. Relationship between Country Governance Indicators and Human Development Index. Gest. E Desenvolv. 2019, 16, 53-70. [CrossRef]

43. Khan, N.H.; Ju, Y.B.; Hassan, S.T. Modeling the Impact of Economic Growth and Terrorism on the Human Development Index: Collecting Evidence from Pakistan. Environ. Sci. Pollut. Res. 2018, 25, 34661-34673. [CrossRef]

44. Biggeri, M.; Mauro, V. Towards a more 'Sustainable' Human Development Index: Integrating the Environment and Freedom. Ecol. Indic. 2018, 91, 220-231. [CrossRef]

45. Lee, E.; Jung, K.; Sul, J. Searching for the Various Effects of Subprograms in Official Development Assistance on Human Development across 15 Asian Countries: Panel Regression and Fuzzy Set Approaches. Sustainability 2019, 11, 1152. [CrossRef]

46. Mochizuki, J.; Naqvi, A. Reflecting Disaster Risk in Development Indicators. Sustainability 2019, 11, 996. [CrossRef]

47. Liu, G.; Brown, M.T.; Casazza, M. Enhancing the Sustainability Narrative through a Deeper Understanding of Sustainable Development Indicators. Sustainability 2017, 9, 1078. [CrossRef]

48. Krylovas, A.; Dadelienè, R.; Kosareva, N.; Dadelo, S. Comparative Evaluation and Ranking of the European Countries Based on the Interdependence between Human Development and Internal Security Indicators. Mathematics 2019, 7, 293. [CrossRef]

49. Alexy, M.; Kacer, M.; Rehak, S. Creative Capacity of European Countries. Hung. Geogr. Bull. 2018, 67, $201-222$. [CrossRef]

50. Greene, W.H. Econometric Analysis, 5th ed.; Upper Saddle River: Prentice Hall, NJ, USA, 2003; pp. 1-828.

51. Hsiao, C. Analysis of Panel Data, 3rd ed.; Cambridge University Press: New York, NY, USA, 2003; pp. 1-20.

52. Husek, R.; Pelikan, J. Applied Econometrics: Theory and Practice, 1st ed.; Professional Publishing: Prague, Czech Republic, 2003; pp. 1-263.

53. Wooldridge, J. Econometric Analysis of Cross Section and Panel Data, 1st ed.; The MIT Press: London, UK, 2002; pp. 1-776. 
54. Arellano, M. Panel Data Econometrics: Advanced Texts in Econometrics, 1st ed.; Oxford University Press: Oxford, UK, 2003; pp. 1-248.

55. Nunes, C.; Capistrano, G.; Ferreira, D.; Mexia, J.T. Exact Critical Values for One-Way Fixed Effects Models with Random Sample Sizes. J. Comput. Appl. Math. 2019, 354, 112-122. [CrossRef]

56. Fotiadis, A.; Nuryyev, G.; Achyldurdyyeva, J.; Spyridou, A. The Impact of EU Sponsorship, Size, and Geographic Characteristics on Rural Tourism Development. Sustainability 2019, 11, 2375. [CrossRef]

57. Vevere, V.; Zvirgzdina, R.; Linina, I. Indexes as Business Environment Characterizing Instruments. Eur. Integr. Stud. 2017, 11, 220-232. [CrossRef]

58. Abraham, T.W.; Ahmed, U.A. Economic Growth and Human Development Index in Nigeria: An Error Correction Model Approach. Int. J. Adm. Dev. Stud. 2011, 2, 239-254.

59. Simionescu, M. Competitiveness and Economic Growth in Romanian Regions. J. Compet. 2016, 8, 46-60. [CrossRef]

60. Kordalska, A.; Olczyk, M. Global Competitiveness and Economic Growth: A One-Way or Two-Way Relationship? Inst. Econ. Res. Work. Pap. 2015, 63, 1-15. [CrossRef]

61. Stec, M.; Grzebyk, M. The Implementation of the Strategy Europe 2020 Objectives in European Union Countries: The Concept Analysis and Statistical Evaluation. Qual. Quant. 2018, 52, 119-133. [CrossRef] [PubMed]

62. Dobrovic, J.; Gallo, P.; Mihalcova, B.; Stofova, L.; Szaryszova, P. Competitiveness Measurement in Terms of the Europe 2020 Strategy. J. Compet. 2018, 10, 21-37. [CrossRef]

63. Onyusheva, I. Analytical and Managerial Issues of Human Capital in Conditions of Global Competitiveness: The Case of Kazakhstan. Pol. J. Manag. Stud. 2017, 16, 198-209. [CrossRef]

64. European Union. Annual Report on European SMEs 2017/18. 2018. Available online: https://publications. europa.eu/en/publication-detail/-/publication/a435b6ed-e888-11e8-b690-01aa75ed71a1language-en (accessed on 10 December 2018).

65. Suh, C.J.; Lee, I.T. An Empirical Study on the Manufacturing Firm's Strategic Choice for Sustainability in SMEs. Sustainability 2018, 10, 572. [CrossRef]

(C) 2019 by the authors. Licensee MDPI, Basel, Switzerland. This article is an open access article distributed under the terms and conditions of the Creative Commons Attribution (CC BY) license (http://creativecommons.org/licenses/by/4.0/). 